Finisterra, XXXVII, 74, 2002, pp. 5-31

\title{
CARACTERIZAÇÃO GEO-ECOLÓGICA DOS SISTEMAS DE CORDÕES DUNARES DA ESTREMADURA
}

\author{
(Nazaré, S. Martinho do Porto e Peniche-Baleal)
}

\author{
Maria Virgínia Henriques ${ }^{1}$ \\ CARlos Neto ${ }^{2}$
}

\begin{abstract}
Resumo - O sector litoral da Estremadura entre a Nazaré e Peniche apresenta grande heterogeneidade de formas. Predominam os sistemas de arriba modelados em rochas detríticas e carbonatadas, interrompidos por incisões, controladas pela tectónica. Nelas se localizam as desembocaduras fluviais e, por vezes, se acumulam cordões litorais e praias. Os sistemas de praia correspondem a cerca de $40 \%$ da linha de costa, associados a cordões dunares de forma, dimensão e taxas de cobertura vegetal, variáveis. Estes cordões dunares localizam-se no limite interno da praia ou mesmo na praia alta quando esta se encontra em erosão e ter-se-ão acumulado sobre restingas coalescentes e progradantes que já no Período Histórico isolaram os estuários lagunares existentes a oriente. As características geo-ecológicas exibidas permitiram identificar cordões dunares duplos, separados por depressão ou corredor interdunar, na Nazaré, S. Martinho do Porto e Peniche (Consolação) e um cordão dunar simples no Baleal. Esta diferenciação poderá relacionar-se com as características morfológicas, exposição local ao clima de agitação marítima, regime de ventos e cobertura vegetal.

No que respeita à flora e vegetação, os vegetais pioneiros, psamofílicos e halonitrofílicos que colonizam os ecossistemas de praia média e transição para a praia alta constituem, na área estudada, a associação Salsolo kali-Cakiletum aegyptiacae. É dominada por terófitos primaveris de fraca abundância-dominância, relacionados com os locais de acumulação de restos orgânicos.

As áreas planas da praia alta, atingidas pela ondulação durante as marés vivas e tempestades, são colonizadas por uma formação vegetal aberta, dominada por Elymus boreli-atlanticus (associação Euphorbio-Agropyretum junceiformis). Nas nebkas da praia alta e nas cristas das ondulações da duna branca aparece a associação Loto-Ammophiletum, dominada por Ammophila australis, com elevada abundância-dominância, acompanhada por Otanthus maritimus e Lotus creticus. A duna cinzenta, mais afastada das influências oceânicas (vento e salinidade), caracteriza-se por relativa estabilidade das areias e sucessão de cristas de duna e corredores interdunares, ocupados pela associação termófila Armerio welwitschii-Cruciannelletum. As clareiras são ocupadas pela associação terofítica de carácter
\end{abstract}

1 Departamento de Geociências, Universidade de Évora, Apartado 94, 7002-554 Évora. Email: virginia@uevora.pt

2 Departamento de Geografia, Universidade de Lisboa, Alameda da Universidade, 1400-214 Lisboa. Email: netocarlos@clix.pt 
atlântico Violo-Silenetum litoreae. A etapa madura do sistema é constituída, nas dunas estabilizadas mais interiores, por uma formação arbustiva densa e alta dominada por Juniperus turbinata (Osyrio-Juniperetum turbinatae).

Palavras-chave : cordões dunares, dinâmica eólica e litoral, geo-ecologia, sintaxonomia

\begin{abstract}
GEO-ECOLOGYCAL STUDY OF SOME DUNE SYSTEMS IN THE PORTUGUESE estremadura. The Portuguese Estremadura coastal area between Nazaré and Peniche displays great variety of landforms. Most are cliff systems cut in sedimentary rocks with incisions controlled by tectonic activity. In the river mouths sand bars and beaches are present. Beach systems make up about $40 \%$ of the referred coastline and have ridges of diverse form and size, and rates of vegetation cover. These dunes appear on the inland side of the beach or even backshore as a result of erosion. They may have piled up into sand backs that cut off the lagoon estuaries to the West in the historic period. The geomorphologic and sedimentary characteristics that appear permit the identification of double ridges separated by interdunal corridors or depressions in West Nazaré, S. Martinho do Porto and Peniche (Consolação) and in a simple and continuous form in Baleal. This difference could be related with local topography, wind/wave climatology and/or vegetation cover. With regard to flora and vegetation, psammphitic and halonitrophilous pioneer plants that colonise foreshore ecosystems and transitions to backshore are Salsolo kali-Cakiletum aegyptiacae in the studied area. Springtime terophitic is sparse and grows where organic remains have accumulated. Flat backshore areas which are overrun by sea during spring-tides and storms are colonised by open vegetation, predominantly Elymus boreli-atlanticus (Euphorbio-Agropyretum junceiformis). Alongside the clumps of marran grass, on the backshore and on the crests of white dunes, Loto-Ammophiletum grows abundantly together with Otanthus maritimus and Lotus creticus. Grey dunes, which are further away from the effects of the ocean (winds and salinity), are characterised by relative sand stability and a succession of dune peaks and interdune corridors with thermophilic associated Armerio welwitschii-Cruciannelletum. The openings display terophitic associated Violo-Silenetum litoreae with Atlantic features. The mature stage of the system consist in the more interior stabilised dune of dense shrubs, consisting mostly of Juniperus turbinata (Osyrio-Juniperetum turbinatae).
\end{abstract}

Key words : dune systems, coastal and eolic dynamics, ecology, syntaxonomic scheme.

\title{
I. INTRODUÇÃO
}

A faixa litoral situada entre a Nazaré e Peniche constitui uma unidade geomorfológica distinta por ser dos raros trechos da costa portuguesa com orientação rígida a $\mathrm{NW}\left(\mathrm{N} 45^{\circ} \mathrm{E}\right)$ resultante da estrutura da depressão diapírica das Caldas da Rainha, situada a oriente (fig. 1). A sul do promontório da Nazaré inicia-se uma costa de arriba, intercalada por pequenas praias formadas na desembocadura dos cursos de água principais, associadas a cordões dunares. No litoral adjacente, o transporte real de sedimentos é inferior ao transporte potencial (ABECASSIS, 1997) devido à proximidade do canhão submarino da 


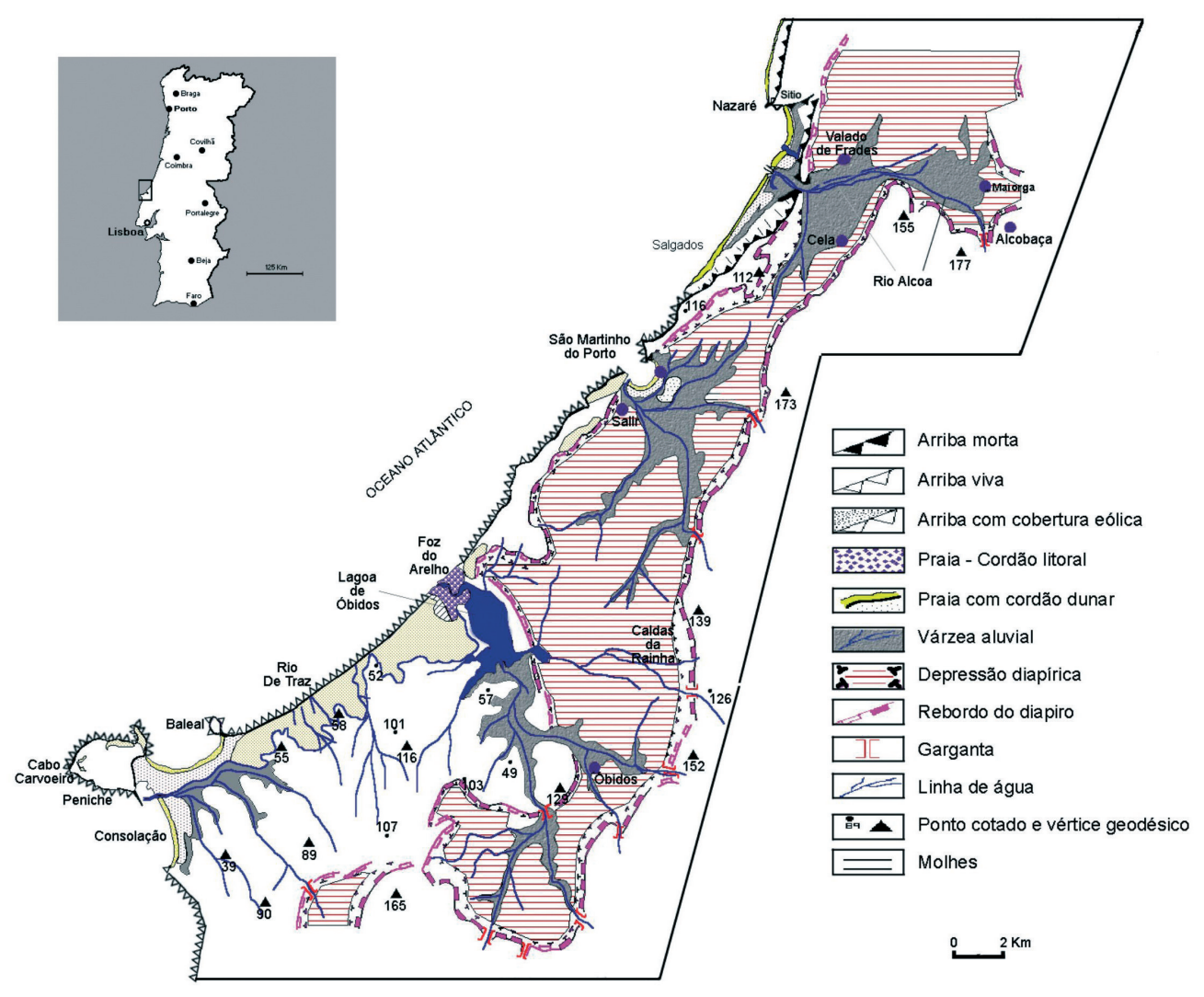

Fig. 1 - Esboço morfológico do litoral entre Nazaré e Peniche.

Fig. 1 - Morphological sketch of the coast between Nazaré and Peniche.

Nazaré, à reduzida largura da plataforma continental, à ausência de tributários fluviais importantes e à presença da Lagoa de Óbidos que funciona como local de deposição de sedimentos.

A área considerada apresenta grande heterogeneidade de formas litorais, das quais $40 \%$ da linha de costa referida corresponde a sistemas de praia. Nestes, $75 \%$ são constituídos por praias com limite interior (antepraia) modelado em dunas associadas em cordões dunares simples (Baleal), ou duplos (praias da Nazaré-Salgados, S. Martinho do Porto e Consolação), de configuração semelhante. Por se tratar de formas modeladas em sedimentos, a variedade dos geossistemas depende das características destes e das formas do relevo. A forma e orientação das cristas geram sectores com diferentes condições mesológicas (temperatura, humidade, circulação de vento, salinidade, granulometria dos sedimentos, matéria orgânica e $p H$ do solo), colonizados por associações vegetais distintas. 


\section{DESCRIÇÃO GEO-ECOLÓGICA DOS SISTEMAS}

\section{Cordões dunares do arco litoral Nazaré-Salgados}

\section{Geomorfologia}

Os cordões dunares do sector Nazaré-Salgados estabelecem o limite superior da praia (antepraia) e prolongam-se para o interior à várzea de S.Gião-Nazaré e à arriba morta dos Salgados, numa área de cerca de 120 hectares (fig. 2). Estão modelados sobre um conjunto de cristas de praia ou restingas coalescentes, relacionadas com a evolução do estuário lagunar que ocupou os sectores baixos do extremo norte da depressão diapírica das Caldas da Rainha (Valado, Cela e Maiorga), denunciando uma corrente de deriva litoral local com direcção predominante S-N (resultante da inversão da deriva N-S pelo promontório da Nazaré). É a sul da Nazaré que o sistema se apresenta mais desenvolvido, pois o efeito de abrigo aos ventos dominantes, causado pelo promontório, deixa de se fazer sentir. Individualizam-se dois cordóes dunares paralelos (interior e exterior), separados por um corredor interdunar estreito, contínuo e quase rectilíneo.

O cordão dunar interior, afastado do mar e enraizado na base dos depósitos do grande deslizamento fóssil dos Salgados, estende-se até ao paúl da Algerifeira onde termina, em forma de báculo, de encontro à arriba morta

da Pescaria. É constituído por um conjunto de dunas parabólicas, orientadas NW-SE, cujas cristas atingem $25 \mathrm{~m}$ de altitude. A forma parabólica resulta da erosão turbilhonar exercida pelos ventos de NW, sobre dunas inicialmente paralelas à costa. Algumas cristas exibem forma multilobada resultante da coalescência das pontas de dunas parabólicas, em movimento para SE. Junto à Algerifeira, o cordão apresenta forma caótica resultante da extracção de grandes volumes de areias (nas décadas de 70 e 80). Esta intervenção destruiu parte das cristas e originou depressões artificiais, escavadas abaixo do nível freático e por isso inundadas e transformadas em lagoas de água salobra. A destruição das formas e do coberto vegetal desencadeou a formação de novos corredores de deflação e a acumulação de domas arenosas sobre as estruturas anteriores à intervenção, gerando uma morfologia complexa.

O cordão dunar exterior inicia-se no limite superior da praia. É paralelo ao anterior até ao paúl da Algerifeira, destacando-se deste por um corredor ou depressão interdunar (fig. 2). Para norte do paúl o cordão é simples e contínuo, apenas interrompido pela barra do rio Alcoa e pelo porto de abrigo. A barra, antes de estabilizada (finais do século XIX), migrava de acordo com a direcção e intensidade das correntes de deriva e de descarga fluvial que rompiam e erodiam o cordão. Tal como o cordão interior, este apresenta forma em báculo (junto à antiga desembocadura), com a curvatura para oriente, sugerindo dinâmica semelhante. Entre a Nazaré e a actual desembocadura, a topografia do cordão encontra-se alterada relativamente à sua forma inicial, em consequência 


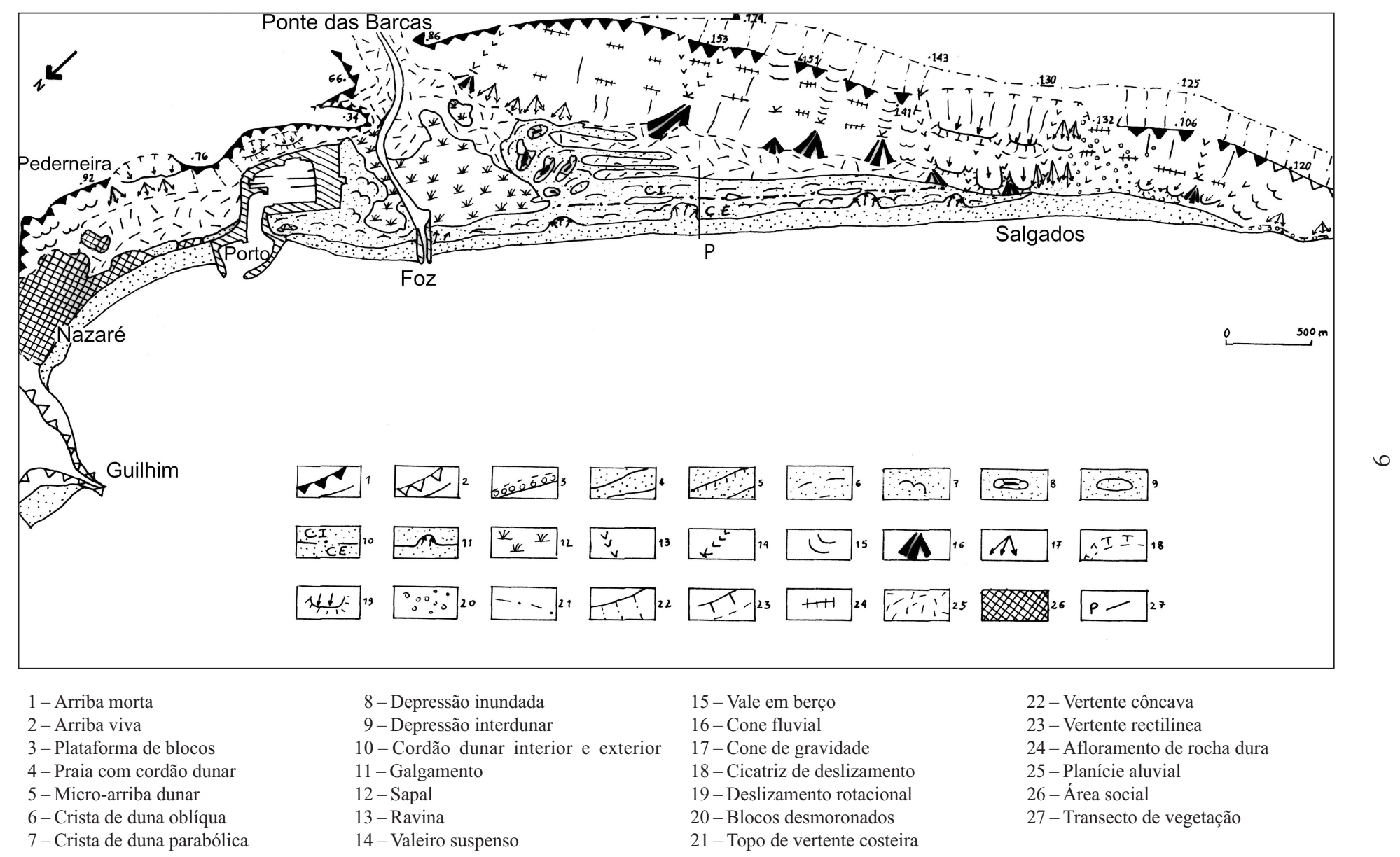

Fig. 2 - Morfologia do sistema litoral da Nazaré.

Fig. 2 - Morphology of Nazaré litoral system. 
da expansão urbana, da construção do porto de abrigo (década de 80) e do desvio da foz do rio Alcoa.

A composição petrográfica dos sedimentos dos cordões dunares é semelhante à da praia alta, embora com maior percentagem de quartzo leitoso e róseo. Os grãos exibem aspecto mais baço e rolado, com superfície irregular e vestígios de óxido de ferro, cuja presença aumenta no cordão interior, em função do incremento da pedogénese, devido ao maior desenvolvimento do coberto vegetal.

\section{Flora e vegetação}

Nos cordões dunares identificou-se a seguinte sucessão geo-ecológica: praia alta, duna branca, duna cinzenta, depressão interdunar, duna castanha e duna verde (fig. 3).

Na praia alta acumulam-se nebkas ou pequenas dunas embrionárias de dimensão variável, colonizadas por espécies halopsamófilas (Otanthus maritimus, Calystegia soldanella e Eryngium maritimum) bem adaptadas ao soterramento, com sistema radicular desenvolvido e taxa de cobertura 1 (fig. 3). Nos locais de maior concentração de sedimentos grosseiros, identificou-se ainda Crithmum maritimum, ausente nos cordões mais a sul. A associação vegetal destas formas embrionárias constitui o primeiro estádio da sucessão natural da vegetação, cuja preservação é crucial na manutenção e evolução destas formas.

A duna branca com altura variável é modelada em cristas separadas por corredores de deflação. A primeira crista possui cobertura vegetal fraca e descontínua (daí a designação de duna branca), predominando Ammophila australis, Crucianella maritima e Medicago marina, para além da penetração de espécies das nebkas adjacentes. Acantonadas na vertente sotamar surgem Helicrysum picardi, Armeria welwitschii, Lotus creticus, assim como Sedum sediforme e Seseli tortuosum, frequentes nos locais de maior erosão antrópica, substi-tuindo a Crucianella maritima. Estas espécies são comuns ao ecossistema da duna cinzenta (S. CRUZ, 1984). A sua presença neste sector e a forma do perfil transversal da duna são indicadores da degradação do sistema. À primeira crista segue-se pequena depressão, acidentada por dunas transversais instáveis, quase desprovida de vegetação (algumas manchas de Otanthus maritimus, Corema album, Seseli tortuosum, apenas identificadas no sistema da Nazaré e Antirrhinum cirrhigerum e Iberis procumbens). Nalguns locais existe ainda segunda crista, parabólica, mais alta e colonizada por Ammophila australis, Ononis natrix e Antirrhinum cirrhigerum. Esta associação fitogeográfica estabelece a passagem do estádio pioneiro à associação ou sub-associação da duna cinzenta, dada a irregularidade da cobertura nas cristas, a instabilidade das areias e o baixo teor de matéria orgânica no solo.

A duna cinzenta, mais alta (10 a $25 \mathrm{~m})$, exibe vegetação arbustiva a sub-arbustiva, que confere ao conjunto estabilidade e coloração mais escura. A maior taxa de cobertura corresponde à vertente sotamar, abrigada e mais 


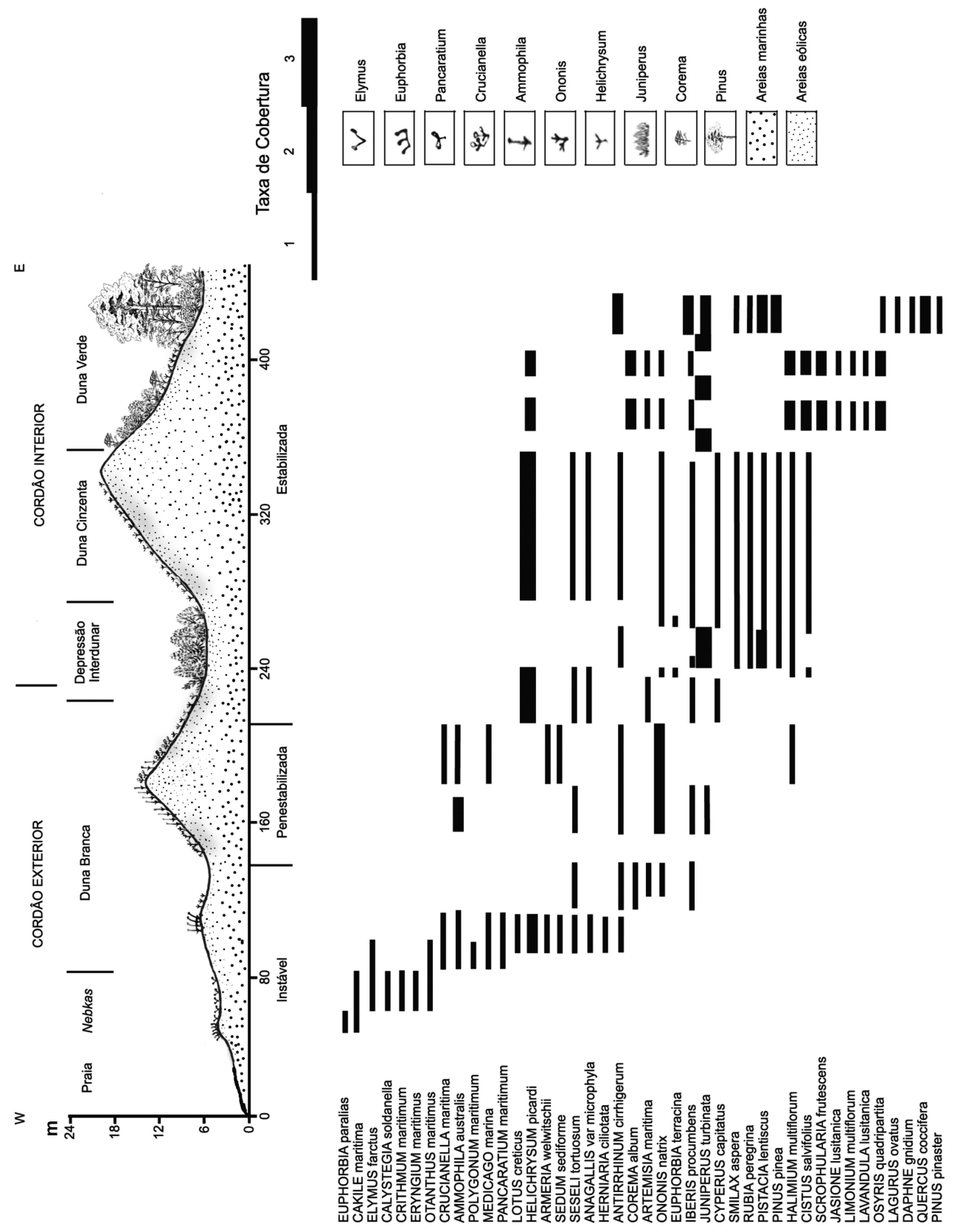

Fig. 3 - Perfil morfo-ecológico dos cordões dunares da Nazaré (levantamento de campo executado em Maio de 2000).

Fig. 3-Morpho-ecological profile of Nazaré sand dune ridges (field work, May 2000). 
quente, colonizada por termófilas já presentes na duna branca (Ammophila australis, Ononis natrix, Antirrhinum cirrhigerum) e Halimium multiflorum. Esta comunidade dá, sem interrupção, lugar às espécies da depressão interdunar.

A depressão interdunar estabelece a separação entre o cordão interior e exterior. O solo possui elevado teor de matéria orgânica (49\%), condições de abrigo e humidade favoráveis ao desenvolvimento de vegetação arbustiva ou arbórea com taxa de cobertura vegetal próxima dos $100 \%$. No fundo da depressão predominam as espécies Juniperus turbinata, Pistacia lentiscus, Helichrysum picardii, Seseli tortuosum, Cyperus capitatus e Iberis procumbens.

A duna castanha engloba o sector barlamar do cordão interior colonizado por Helichrysum picardii em associação com alguns exemplares de Cistus salvifolius e Pinus pinea. O conjunto atinge uma taxa de cobertura vegetal de cerca de $90 \%$.

A duna verde ocupa a vertente continental do cordão interior, marginando pequenas depressões húmidas. Mais afastada da influência do mar e abrigada do vento, possui elevado teor (48\%) de matéria orgânica. Predomina a espécie Juniperus turbinata, acompanhada por Helichrysum picardii, Lavandula lusitanica, Artemisia campestris, Halimium multiflorum, Iberis procumbens, Smilax aspera, Pistacia lentiscus, Daphne gnidium, Quercus coccifera, Pinus pinea e Pinus pinaster.

\section{Dinâmica do sistema}

Entre a foz do rio Alcoa e a praia dos Salgados o sistema encontra-se em erosão a partir da praia alta (berma), onde se observa uma micro-arriba talhada na duna primária, com $1-2 \mathrm{~m}$ de altura e declives superiores a $35^{\circ}$, no Inverno. O talude é galgado pelas correntes de afluxo nas marés vivas e nas tempestades, aproveitando os corredores ou depressões causadas pelo vento e/ou pisoteio. No Verão, a arriba dunar atenua-se, pois a ausência de tempestades e o aumento da evapotranspiração, facilitam a secagem, mobilização e posterior acumulação das areias contra o talude herdado da estação anterior, originando as nebkas. A presença da micro-arriba dunar e o recuo desta para o interior denunciam aspectos de degradação deste cordão.

A superfície ocupada pelo conjunto dunar ${ }^{3}$ diminuiu de cerca de 10 hectares entre 1912 e 1958 e 20 hectares de 1958 a 1989 de que resultou o estreitamento do cordão interior. As alterações mais recentes devem-se à extracção de areias, às obras portuárias e à erosão marinha da frente da duna primária, em consequência do emagrecimento do perfil médio da praia.

3 «Plano Hydrográphico da Enseada da Pederneira» (1912) e Fotografias Aéreas (voo Americano, esc. 1:26 000, 1958; voo do Litoral da Estremadura, escala 1:15 000, 1989). 


\section{Os cordões dunares de S. Martinho do Porto}

\section{Geomorfologia}

O sistema dunar de S. Martinho do Porto engloba dois cordões semi-circulares, separados por uma faixa de aluviões onde corre, num canal artificial, a Vala Real dos Medros (fig.4). Encontra-se bem desenvolvido a sul e sudeste, estreitando para norte.

O cordão dunar exterior (fig. 4) inicia-se na praia alta (que nem sempre existe) e estende-se até à foz do rio da Tornada e ao caminho-de-ferro, numa

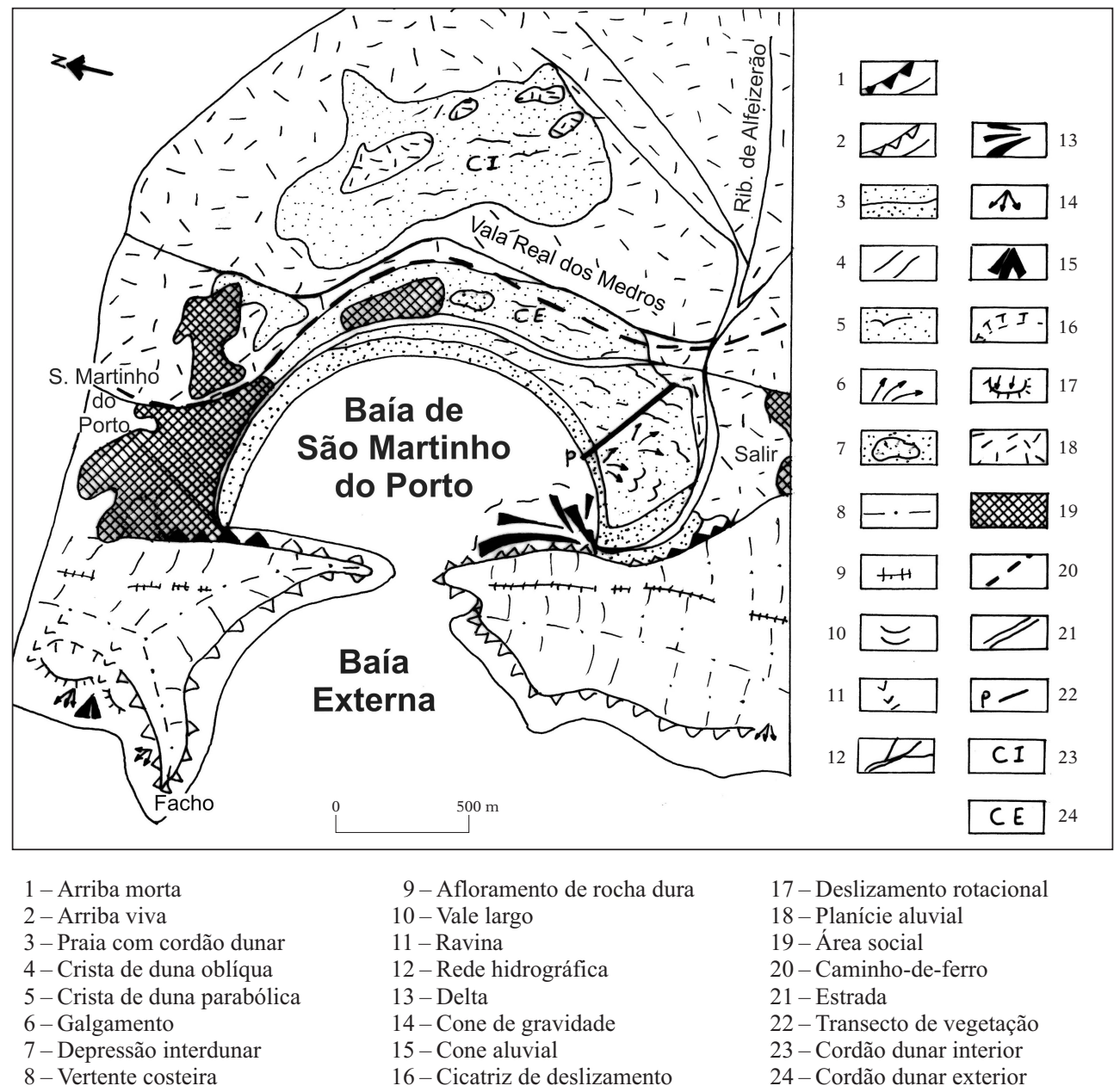

Fig. 4 - Morfologia do sistema litoral de S. Martinho do Porto.

Fig. 4 - Morphology of S. Martinho do Porto litoral system. 
área de cerca de 5 hectares. As cristas estão orientadas para SSE (na trajectória dos ventos de NNW), com forma parabólica ou oblíqua e 10-15m de altitude. $\mathrm{O}$ cordão estreita junto à povoação de $\mathrm{S}$. Martinho, devido ao abrigo da arriba do Facho, aumentando progressivamente de largura para sul, onde se identificam cristas paralelas, separadas por corredores de deflação.

O cordão dunar interior, paralelo ao primeiro, possui morfologia semelhante, mas está dele bem destacado. Apresenta também maior espessura na direcção do enfiamento da barra da baía e está confinado pelo traçado da rede hidrográfica (a poente a Vala Real dos Medros, a nascente a ribeira da Amieira e a sul o rio da Tornada (fig. 4). As cristas são aqui menos desenvolvidas e mais baixas $(7-11 \mathrm{~m})$ e estão, em alguns locais, estabilizadas por pinheiro bravo, noutros, em erosão causada pela ocupação humana.

A análise morfoscópica das areias não permitiu diferenciar pela composição petrográfica ou pela forma os sedimentos dos dois cordões. Em ambos foram identificados grãos de quartzo hialino, subangulosos a arredondados, pouco brilhantes na duna primária, aumentando para o interior a percentagem de grãos baços e picotados. Estas características, assim como a presença da mica proveniente do trânsito litoral, constituem indicadores de transporte a maior distância da fonte de alimentação.

\section{Flora e vegetação}

A partir do mar observou-se uma sucessão geo-ecológica pouco estruturada: nebka incipiente; duna branca ( $1 .{ }^{\mathrm{a}}$ crista, corredor de deflação, $2 .^{\mathrm{a}}$ crista); duna cinzenta interrompida por corredores de deflação e domas de areia; duna verde (fig. 5).

As nebkas, só existentes no Verão, são colonizadas por espécies halopsamófilas de fraca taxa de cobertura, predominando Calystegia soldanella, Medicago marina, Elymus boreali-atlanticus e Eryngium maritimum. A ausência de Cakile maritima poderá dever-se à exiguidade da largura da praia alta.

A duna branca, de altura variável (1-10m), modelada em várias cristas separadas por estreitos corredores, é revestida por tufos descontínuos, colonizados predominantemente por Eryngium maritimum, Ammophila australis, Lotus creticus e Pancratium maritimum. No sector interno desta duna sucedem-se várias cristas parabólicas degradadas, sulcadas por corredores multi-direccionais e desprovidas de vegetação. É comum a 2. ${ }^{a}$ crista apresentar maior taxa de cobertura vegetal predominando Artemisia maritima, Crucianella maritima, Malcomia littorea e, por vezes, Vulpia alopecurus e Cyperus capitatus, espécies bem adaptadas a sectores expostos ao vento, salinidade e escassez de matéria orgânica.

As depressões interdunares, mais amplas e interiores possuem taxa de cobertura semelhante à das cristas (1 e 2), exibindo maior complexidade de formas e menor número de espécies do que as da Nazaré ou das áreas mais a sul.

A duna cinzenta, confinada a algumas cristas com 10 a $12 \mathrm{~m}$ de altitude, está presente nas zonas mais abrigadas e estáveis, colonizadas por Helichrysum 


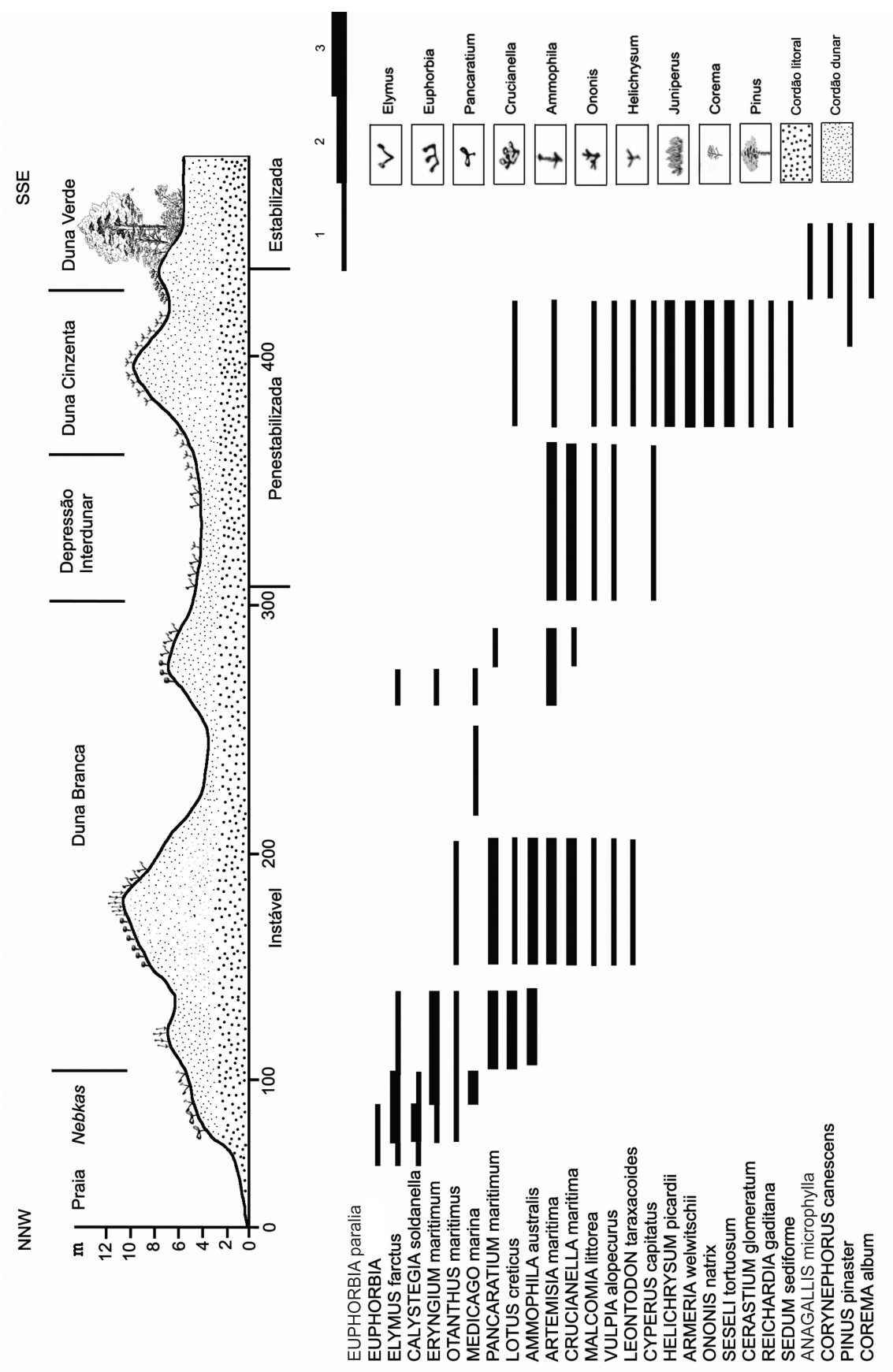

Fig. 5 - Morfologia do sistema litoral da Nazaré.

Fig. 5 - Morphology of Nazaré litoral system. 
picardii, Ononis natrix, Armeria welwitschii e Seseli tortuosum, entre outras com menor taxa de cobertura.

A duna verde restringe-se às zonas mais protegidas da erosão, alternando, no cordão exterior, com sectores de duna cinzenta. Distingue-se pela presença de Anagallis microphylla e Corynephorus maritimus e alguns exemplares de Pinus pinaster. De salientar que no cordão interior a duna verde corresponde a povoamentos quase exclusivos desta última espécie.

\section{Dinâmica do sistema}

Em finais do século XVII a configuração dos cordões sofreu importantes alterações decorrentes da regularização das linhas de água, com a finalidade de minimizar o assoreamento e insalubridade existentes. Os rios da Tornada e de Alfeizerão foram, nessa época, desviados e reunidos num único colector para desaguar a sul e diminuir assim o assoreamento dos canais e a destruição das dunas, substituindo o traçado sinuoso anterior. Mas apesar das intervenções, as inundações eram frequentes e nos anos chuvosos os diques rebentavam e as águas seguiam os declives mais favoráveis, destruindo as dunas ${ }^{4}$. A construção do caminho-de-ferro (finais do século XIX), a abertura da estrada marginal (década de 50), a deposição de dragados (1973 e 1986) e a recente construção de infra-estruturas, modificaram em muito a topografia dunar. Estas intervenções foram nos últimos anos agravadas pelo incremento do pisoteio e circulação de viaturas, cujas consequências têm anulado as tentativas de estabilização artificial das dunas (exceptuam-se as conducentes à interditação de acesso e criação de obstáculos ao vento, executadas em 1993-94, no cordão exterior). Entre 1958 e 1989 a superfície dunar não sofreu grande alteração (1,5 hectares no conjunto). As principais modificações reflectiram-se na variação da altura e forma das cristas assim como na destruição do coberto vegetal.

Todo o ecossistema dunar de S. Martinho do Porto se encontra em degradação comprovada pela presença e recuo da micro-arriba dunar, assim como pela fraca cobertura vegetal das cristas, cuja superfície é rapidamente remobilizada pelo vento e colonizada por Ammophila australis.

\section{Os cordões dunares do tômbolo de Peniche}

Encontram-se modelados sobre as restingas que estabelecem a ligação de Peniche ao continente (fig. 6), formando um tômbolo saliente para ocidente, muito exposto aos ventos de $\mathrm{N}$ e $\mathrm{SW}$ que aqui encontram o primeiro obstáculo à sua trajectória. O tômbolo é formado por dois cordões dunares, o do Baleal, a Norte, e o da Consolação, a Sul. A separação entre os sistemas faz-se na área da Prageira, onde não existe duna mas um sapal baixo, parcialmente recuperado. Os cordões apresentam forma semelhante (em arco) mas orientação oposta,

4 Relatos de M. Franzini (1821). 


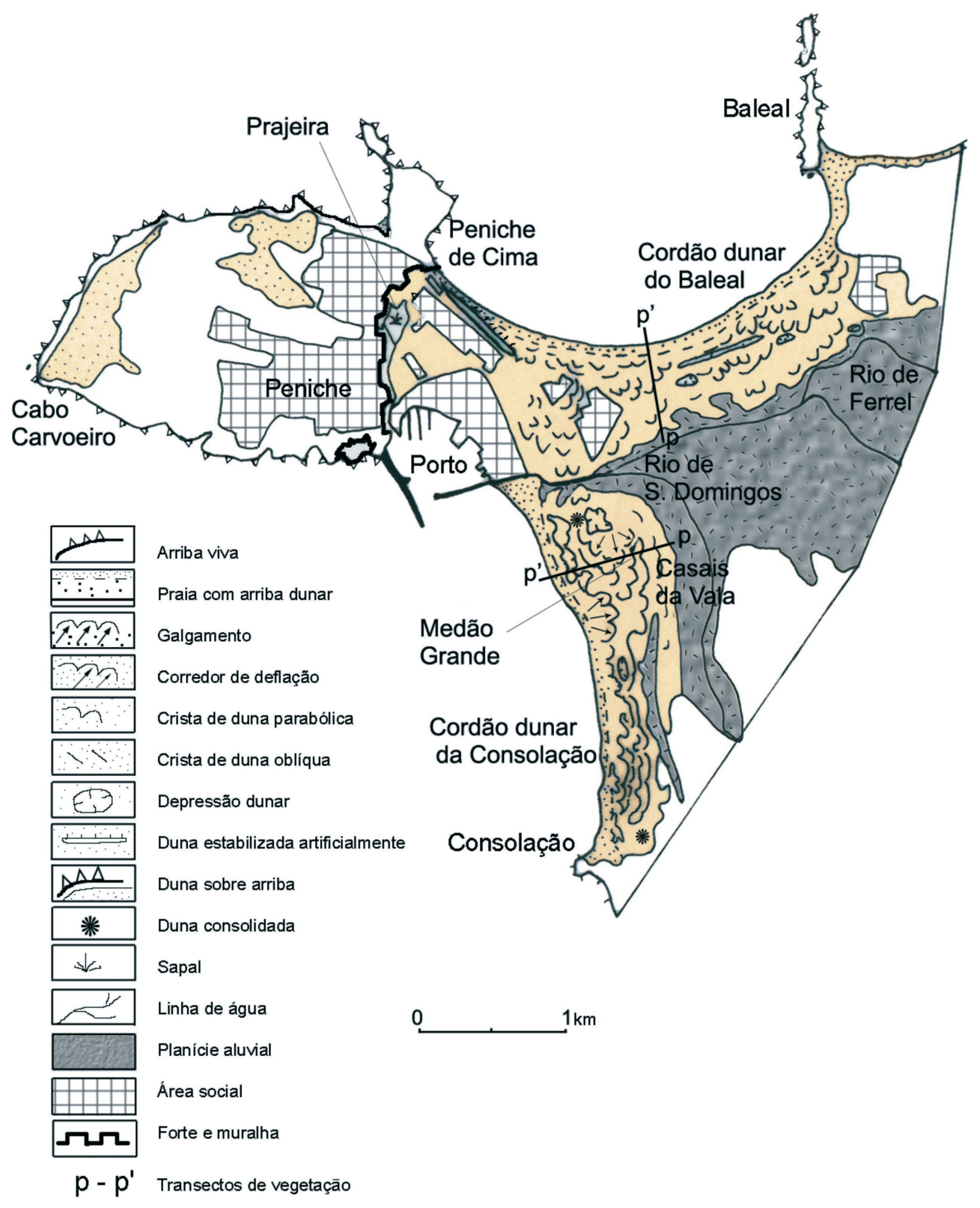

Fig. 6 - Morfologia do sistema litoral de Peniche.

Fig. 6-Morphology of Peniche littoral system. 
razão porque possuem dinâmicas de evolução e fontes de alimentação diferenciadas. Por esta razão, embora pertençam à mesma unidade geomorfológica serão apresentados separadamente.

\subsection{O cordão dunar do Baleal}

\section{Geomorfologia}

Entre o Baleal e Peniche de Cima, o cordão dunar está modelado sobre o cordão litoral que liga a ilha de Peniche ao continente (tômbolo norte), ocupando cerca de 135 hectares. Apresenta forma arqueada, boa exposição aos quadrantes de N e NW, prolongando-se à planície aluvial adjacente, numa faixa de cerca de $1 \mathrm{~km}$ de largura (fig. 6). Inicia-se na praia alta ou na antepraia (quando existe) por uma micro-arriba de altura variável (2-3m no Inverno), onde estratificação entrecruzada e um complexo sistema radicular da vegetação asseguram, em alguns locais, a manutenção de declive acentuado. Prolonga-se para oriente até à planície aluvial do rio de $\mathrm{S}$. Domingos e termina junto a Peniche por uma duna frontal alta $(10-15 \mathrm{~m})$ estabilizada artificialmente nos anos 80 .

O cordão é simples e compreende, em perfil transversal (fig. 7), uma duna branca frontal, baixa (3-5m de altitude), regular e quase desprovida de vegetação; um pequeno corredor eólico e um conjunto de cristas oblíquas e parabólicas com $12-17 \mathrm{~m}$ de altitude, orientadas para S, SSW, ou SE, de acordo com o recorte da costa e a exposição aos ventos dominantes. As várias cristas estão também separadas por depressões e corredores, onde se movimenta grande volume de areia que alimenta as domas arenosas acumuladas contra as cristas mais salientes, renovando a topografia. Em alguns casos estas domas resultam da actuação de ventos mais fortes, sobre dunas parabólicas com cobertura vegetal degradada.

Os sedimentos dunares apresentam composição litológica semelhante à da praia (cerca de $90 \%$ de grãos de quartzo hialino, $9 \%$ de bioclastos de $1 \%$ quartzo róseo e leitoso). A percentagem de bioclastos é elevada na duna primária (11\%) e nos corredores de deflação (13\%), diminuindo para o interior (8\%), ao contrário da matéria orgânica. Na duna frontal os grãos apresentam aspecto brilhante e sub-rolado, aumentando para o interior a percentagem de grãos rolados e baços. Nos corredores o rolamento é mais acentuado e alguns grãos apresentam marcas de impacto, provocadas pelo turbilhonamento.

Algumas sondagens executadas no cordão ${ }^{5}$ indicam um depósito de 4-6m de areias eólicas, assentes sobre lodos (espessura de 2-4m), correlativos de ambiente estuarino ou lagunar, sobre formações marinhas (areias com conchas). O substrato jurássico encontra-se a cerca de $-6 \mathrm{~m}$ na base do cordão dunar e a $-4 \mathrm{~m}$ junto a Peniche de Cima (onde termina o cordão). Depósito

5 Sondagens realizadas no interior do cordão do Baleal, nas imediações do rio de S. Domingos para construção de infra-estruturas. 
19

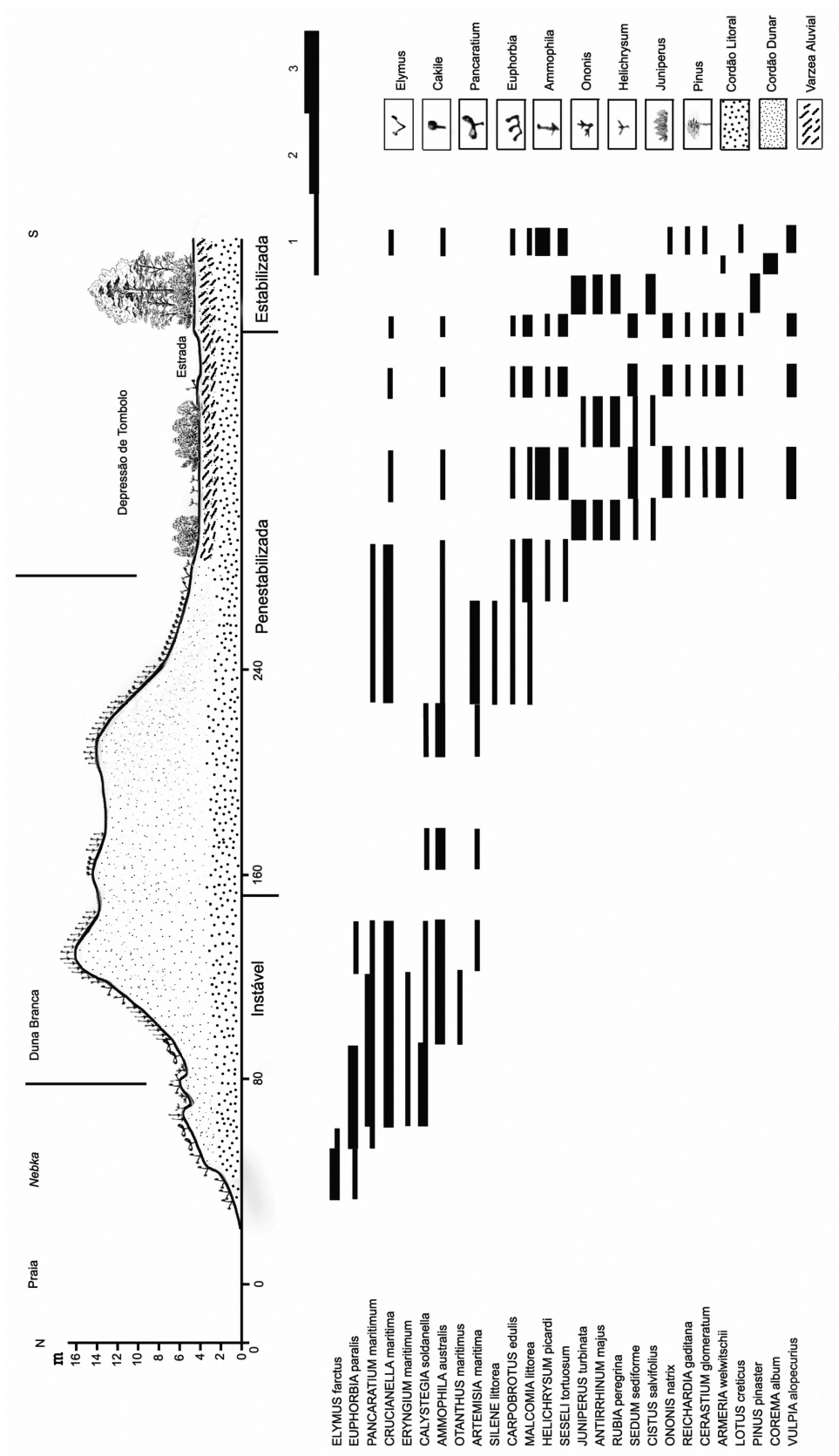

Fig. 7 - Perfil morfo-ecológico do cordão dunar do Baleal (levantamento de campo executado em Maio de 2000).

Fig. 7-Morpho-ecological profile of Baleal sand dune ridge (field work, May 2000). 
lodoso semelhante ao descrito pode observar-se no terraço de maré baixa, junto ao Baleal, quando o perfil da praia se encontra emagrecido pela acção dos temporais. Junto ao porto de Peniche estes depósitos lodosos não estão presentes e o substrato calcário foi encontrado a maior profundidade $(-10 \mathrm{a}-15 \mathrm{~m})^{6}$, coberto por depósitos arenosos com conchas. O cordão terá assim evoluído transgressivamente sobre um sapal, alimentado por uma superfície de deflação existente a ocidente, abaixo do actual nível do mar e com abundância de finos. Os depósitos lodosos poderão corresponder à secção inferior dos rios de S. Domingos e de Ferrel que, antes da formação do cordão litoral do Baleal, desaguariam a norte, direcção do seu traçado actual. Neste caso este cordão seria posterior ao da Consolação.

\section{Flora e vegetação}

A sucessão geo-ecológica observada é mais simples do que a dos sistemas mais a norte: praia alta com nebkas incipientes e locais; duna branca e depressão do tômbolo (fig. 7).

A praia alta, mais extensa no Verão, apresenta nebkas colonizadas por Elymus boreali-atlanticus e Euphorbia paralias, com índice de cobertura 2; a exiguidade da largura da praia e a presença da micro-arriba dunar contribuem para a ausência de Cakile maritima e ocorrência de menor número de espécies.

Nas primeiras cristas de duna branca ocorrem as espécies halopsamófilas Crucianella maritima, Pancaratium maritimum, Calystegia soldanella e Eryngium maritimum, bem adaptadas à forte mobilidade dos sedimentos. Nas segundas, mais altas, de forma parabólica e intercaladas por pequenos corredores e domas, identificaram-se Ammophila australis e Artemisia maritima. Nas vertentes sotamar, a faixa de vegetação é estreita, com taxa de cobertura 2 e elevado número de espécies características, além da Ammophila australis, Crucianella maritima e Pancaratium maritimum comuns a todo o sistema. Identificaram-se ainda Iberis procumbens, Carpobrotus edulis, Malcomia littorea, Helichrysum picardii e Seseli tortuosum.

A depressão do tômbolo apresenta vegetação característica da duna verde. Ocorre no limite interior do cordão, onde as areias escorregadas da vertente sotamar se acumulam sobre a planície aluvial. As condições de abrigo, a proximidade da toalha freática e de solo formado por aluviões, suportam vegetação densa de porte arbustivo a arbóreo. Coexistem espécies típicas da duna branca, cinzenta e verde, predominando Helichrysum picardii, Ononis natrix, Armeria welwitschii, Corema album e Vulpia alopecurus e alguns exemplares de Pinus pinaster. Esta comunidade heterogénea testemunha vários estádios de degradação da vegetação natural típica de cada sector e os vestígios de sucessivos trabalhos de estabilização do sistema através de sementeiras e plantações de espécies arbustivas e arbóreas.

6 Sondagens executadas para projecto de ampliação do Porto de Peniche. 


\section{Dinâmica do sistema}

A instabilidade do cordão dunar do Baleal aparece referida desde meados do século XIX. Entre a praia a sul de Peniche, o Baleal e o rio de Ferrel existiam dunas em deslocação para o interior, impelidas por ventos de $\mathrm{N}$ e NW, «coados pelos rochedos do Baleal e de Peniche» (Ribeiro e Delgado, 1868). A fixação das areias foi feita com plantações de pinheiro-bravo (Pinus pinaster), mato, estorno (Ammophila australis) e zimbro (Juniperus turbinata). Em 1902 é ainda referida a degradação e mobilidade das dunas ocasionada por escassez da vegetação e pelos galgamentos nas marés vivas e tempestades (J. FERREIRA,1902), indicadores do pouco sucesso das campanhas. O problema persiste actualmente pois é reduzido o número de exemplares inventariados, pertencente às espécies introduzidas para fixação.

\subsection{O cordão dunar da Consolação}

\section{Geomorfologia}

O cordão dunar da Consolação desenvolve-se entre o molhe sul do porto de Peniche e o forte da Consolação, numa superfície de cerca de 170 hectares (fig. 8). Está modelado sobre o cordão litoral sul que forma o tômbolo. Apresenta forma ligeiramente arqueada, aberta aos quadrantes de W e SW e abrigada dos ventos de NW pela península de Peniche. A forma e exposição conferem ao sistema morfologia complexa. Identificaram-se dois cordões distintos, separados por uma depressão interdunar.

O cordão dunar exterior inicia-se por uma duna baixa (4-5m) e aplanada no topo, seguida de um estreito corredor de deflação ou depressão gerada pelos galgamentos das ondas de tempestades. A partir deste, ergue-se uma crista declivosa a barlavento e de perfil suave a sotavento, contrário ao normal perfil dunar (fig. 8). Esta assimetria denuncia forte erosão marinha da duna frontal.

O cordão dunar interior estabelece-se a partir da depressão interdunar húmida e prolonga-se para nascente por uma ou várias cristas, mais altas (18-24m de altitude), com declive acentuado a sotavento, terminando abruptamente sobre a planície aluvial ou encostando-se à arriba (junto à Consolação). Neste sector o coberto vegetal é mais denso e a duna encontra-se relativamente estabilizada. A morfologia das cristas varia com a exposição aos ventos dominantes, predominando as dunas parabólicas e oblíquas. A direcção N-S observa-se entre Medão Grande e Casais da Vala (cristas com altitude superior a $20 \mathrm{~m}$ ), onde se faz a penetração dos ventos de $\mathrm{N}$ que atravessam o cordão do Baleal (mais baixo) e se faz sentir o abrigo da península de Peniche aos ventos de NW. Para sul, o cordão é mais estreito e as cristas estão orientadas NW-SE e paralelas à costa, em consequência da acção dos ventos de NW que contornam a península de Peniche e da configuração da linha de costa.

$\mathrm{Na}$ extremidade norte do cordão interior (entre a foz do rio S. Domingos e a fábrica de farinha de peixe) a erosão descobriu retalhos de duna consolidada 


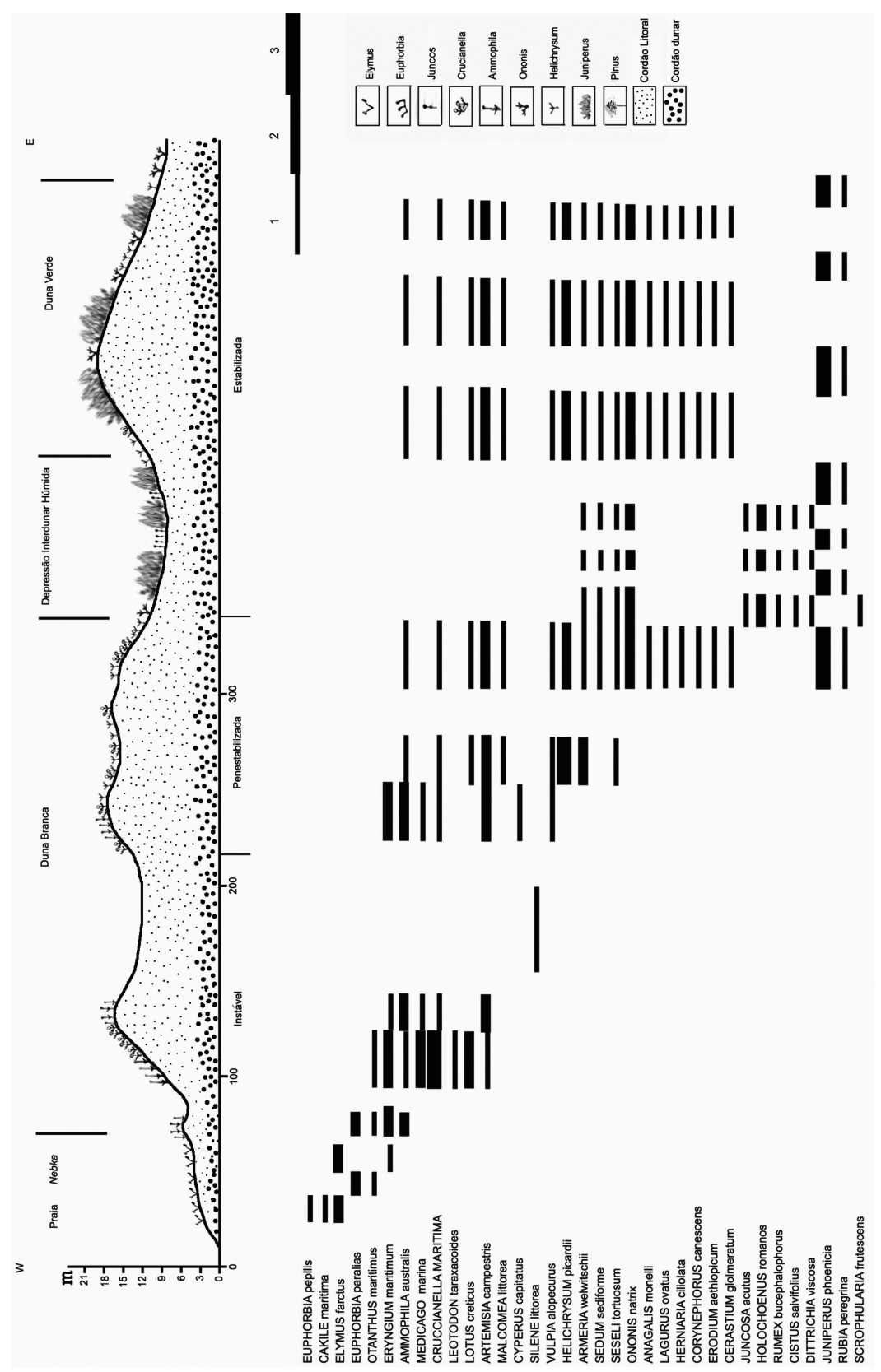

Fig. 7 - Perfil morfo-ecológico do cordão dunar do Consolação (levantamento de campo executado em Maio de 2000).

Fig. 7 -Morpho-ecological profile of Consolação sand dune ridge (field work, May 2000). 
por cimento carbonatado. O maior possui estratificação com orientação $30^{\circ} \mathrm{SE}$, valor semelhante ao observado nas cristas não consolidadas. Junto aos Casais da Vala e na extremidade sul observaram-se outros afloramentos contendo pequenas rizoconcrecções carbonatadas, com estratificação não determinada, devido ao soterramento pela duna cinzenta. Estes retalhos são formados por areias médias a finas $(2,1 \varnothing)$, bem a moderadamente calibradas $(0,63 \varnothing)$, com assimetria muito negativa (-2ø). O teor em carbonatos é muito elevado (45\%) e superior ao valor médio encontrado nas restantes amostras dos cordões (26\%). A composição petrográfica é semelhante à das dunas não consolidadas, embora com menor percentagem de grãos baços e picotados; predomínio dos grãos de quartzo, dos quais 70 a $80 \%$ são sub-angulosos, com superfície polida e brilhante. Bourcart (1936) descreveu dunas consolidadas na área sul de Peniche a que atribuiu idade tirreniana (Cheleense). As características sedimentológicas, a direcção de estratificação e o fraco grau de consolidação observados, levam a considerar as formas consolidadas contemporâneas das dunas não consolidadas que as envolvem. Terão adquirido alguma consolidação pelo facto de se encontrarem mais próximo da toalha freática onde as condições fisico-químicas (salinidade e pH, entre outras) são diferentes. No entanto, poderão ser mais antigas do que as actuais e testemunhar condições climáticas sazonalmente mais contrastadas, tendo posteriormente sido cobertas pelas areias mais recentes. As areias eólicas com consolidação não se observaram a norte de Peniche ${ }^{7}$ e parece-nos ser aqui o seu limite setentrional. Este facto poderá relacionar-se com as condições microclimáticas existentes nesta área (menor precipitação total anual ${ }^{8}$ e diferente intensidade e rumo de ventos ${ }^{9}$ ). No entanto, o elevado teor de clastos carbonatados (provenientes das arribas modeladas em calcários e da plataforma continental, aqui mais larga e menos profunda) presente nas areias é um contributo importante para a formação do cimento carbonatado.

\section{Flora e vegetação}

A sucessão morfo-ecológica observada é comparável à da Nazaré. No cordão exterior: praia alta com nebkas; duna branca; depressão interdunar e duna branca. No cordão interior: duna cinzenta; depressão interdunar húmida; duna castanha e duna verde (fig. 8).

$\mathrm{Na}$ praia alta as nebkas apresentam dois estádios distintos. Formas mais incipientes na base da micro-arriba dunar, acumuladas nos períodos de calma-

\footnotetext{
7 Foram observadas areias com consolidação, dispersas na rampa eólica de Salir do Porto, mas as características granulométricas aproximam-se das registadas em ambientes de praia, pelo que as consideramos como arenitos de praia e não como eolianitos.

8 550mm no Cabo Carvoeiro; 610mm nas Caldas da Rainha.

9 Os ventos predominantes são no Cabo Carvoeiro de N (39\%, $22 \mathrm{~km} / \mathrm{h}), \mathrm{NE}(12 \%, 15 \mathrm{~km} / \mathrm{h})$ e NW $(11 \%, 19 \mathrm{~km} / \mathrm{h})$. Nas Caldas da Rainha, de N (40\%, $12 \mathrm{~km} / \mathrm{h})$, de NW $(19 \%, 9 \mathrm{~km} / \mathrm{h})$, de SE $(24 \%, 9 \mathrm{~km} / \mathrm{h})$.
} 
ria e colonizadas por raros tufos de vegetação halonitrófila (Elymus boreali-atlanticus, Euphorbia peplis). Nas formas mais robustas, e onde a praia alta é mais larga, surge a Cakile maritima e as espécies halopsamófilas (Medicago marina, Otanthus maritimus, Eryngium maritimum e Ammophila australis) que constituem o primeiro estádio na sucessão, com taxa de cobertura baixa.

A duna branca apresenta uma $1{ }^{a}$ crista quase desprovida de vegetação ou com tufos descontínuos de Medicago marina, Crucianella maritima, Artemisia campestris, Malcomia littorea e Leontodom taraxacoides, para além da penetração de espécies identificadas nas nebkas. Os corredores, fechados por vezes por domas transversais, são dominados pelo terófito Silene littorea. A 2. ${ }^{a}$ crista apresenta maior taxa de cobertura e as mesmas espécies referidas para a $1 .^{\mathrm{a}}$, com predomínio de Malcomia littorea e Ammophila australis.

A duna cinzenta corresponde à vertente sotamar da 2. ${ }^{a}$ crista. Por ser mais abrigada é revestida por mato baixo que cobre quase totalmente o solo e é dominado por Armeria welwitschii, Helichrysum picardii e Malcomia littorea.

A depressão interdunar húmida, abrigada e com elevado teor em matéria orgânica (16\%) sustenta uma formação vegetal densa com arbustos e juncos dominada por Rubia peregrina, Rumex hispanicus, Holochoenus australis, Juniperus turbinata, Cistus salvifolius e Juncus acutus.

A duna verde é colonizada por uma comunidade arbustiva de médio porte, muito degradada, que margina a depressão e é dominada por Juniperus turbinata, Cistus salvifolius e Rubia peregrina. É frequente a presença de espécies herbáceas de carácter ruderal e nitrófilo como Anagallis microphylla, Erodium pilosum, Lagurus ovatus, Herniaria ciliolata, Corynephorus maritimus, Cerastium glomeratum, Sedum sediforme, Ononis natrix e Seseli tortuosum.

\section{Dinâmica do sistema}

O cordão dunar encontra-se desigualmente conservado. A norte, junto a Peniche, a construção dos primeiros molhes do porto em 1937 e a estabilização da foz do rio de S. Domingos alteraram a topografia. A modificação da ondulação causada pelas estruturas artificiais, originou o crescimento da praia até ao Forte das Cabanas, aumentando a superfície de deflação com a consequente formação de dunas transgressivas sobre o sapal da Prageira. Esse processo terá sido o responsável por um aumento da superfície da cobertura eólica, relativamente à área cartografada em $1920^{10}$. Em meados dos anos 70 a ampliação do porto destruiu parte da duna envolvente, tendo desaparecido a praia da Ribeira. O mesmo sucedeu ao afloramento do sapal da Prageira, aquando da regularização do canal existente ao longo da muralha. Estas intervenções, em conjunto com a expansão das áreas sociais e de apoio turístico, reduziram a superfície eólica em cerca de 60 hectares, relativamente à área cartografada em 1920.

10 «Plano Hidrográfico da Península de Peniche», 1920, Missão Hidrográfica da Costa de Portugal. 


\section{SÍNTESE FINAL}

As dunas que formam a antepraia do sistema praia-duna agrupam-se em cordões dunares paralelos, modelados sobre restingas coalescentes e transgressivas. O conjunto apresenta forma rectilínea com terminação em báculo (Nazaré-Salgados), ou em arco de círculo (S. Martinho do Porto, Baleal-Peniche) conforme ao recorte da costa e às condições locais de circulação dos ventos. As dunas exibem cristas de forma parabólica ou oblíqua, orientadas para SE, S ou SW.

Na Nazaré, em S. Martinho do Porto e na Consolação, observaram-se dois cordões dunares (ou um cordão dunar duplo): um interno, com maior altitude, estabilizado por vegetação densa; outro externo, mais baixo, instável ou penestabilizado, estabelecido a partir da praia alta. No Baleal identificou-se apenas um, pois está ausente o corredor ou depressão húmida intermédia. A alimentação sedimentar actual é reduzida, dada a pequena dimensão ou curto período de emersão das praias, dos plainos aluviais ou dos pequenos deltas donde provêm os sedimentos. Em geral os cordões dunares evoluem à custa dos seus próprios sedimentos, remobilizados dos corredores de deflação ou dos locais onde a vegetação foi destruída. Deste processo resulta a grande extensão dos sectores de domas arenosas com forma parabólica, acumuladas sobre outros com vários graus de estabilização, gerando morfologia mais complexa que o esquema típico da sucessão geo-ecológica e sedimentos heterométricos.

Em todos os casos estudados as nebkas são formadas por areias grosseiras, lavadas, com $17 \%$ de bioclastos, moderadamente calibradas, aproximadamente simétricas e com escassa percentagem de matéria orgânica. Os sectores de duna branca, mais extensos, exibem areias médias, lavadas, com $15 \%$ de bioclastos, bem a moderadamente calibradas e assimetria negativa. A duna cinzenta apresenta características granulométricas e teor em bioclastos, semelhantes à duna branca, mas com pequena percentagem de matéria orgânica e silte $(0,6 \%)$. As depressões interdunares possuem, em média, maior teor de bioclastos (21\%, com predomínio de fragmentos de gastrópodes terrestres) e de matéria orgânica (3 a 16\%), areias grosseiras, moderadamente calibradas, com assimetria positiva e mesocúrticas. A duna verde é composta por areias bem calibradas, no limite dos valores $(0,47 \varnothing)$ apresentados por FoLK \& WARD (1957) para ambientes de duna. A percentagem de matéria orgânica (14\%) é maior devido à pedogénese e a assimetria é negativa.

As características granulométricas dos sedimentos das dunas diferem da classificação de G. Friedman (1967). Para estes ambientes este autor considerou que as areias de dunas costeiras são bem calibradas, com valores de desvio padrão aproximadamente iguais a $0,35 \varnothing$, valor bastante inferior aos $0,64 \varnothing$, obtidos para o conjunto considerado.

A correlação entre a média e a assimetria calculadas pelo método dos momentos (G. FRIEDMAN, 1961) permitiu verificar que 55\% dos sedimentos apre- 
senta valores característicos das areias de praia (nebkas, depressões e corredores interdunares e o conjunto do cordão dunar da Nazaré); os restantes estão dentro dos valores padrão propostos pelo autor para as areias de duna. A projecção dos valores da média e do desvio padrão, no gráfico de correlação definido pelo mesmo autor (1969), indica para $40 \%$ das amostras valores típicos das areias de rio (cordão da Nazaré, dunas da praia alta, corredores e depressões do Baleal e Consolação), por serem mais grosseiras e pior calibradas do que as de duna. Os valores da assimetria são negativos no sistema da duna branca, cinzenta e verde e aproximadamente simétricos nos restantes, o que está em desacordo com a opinião da maioria dos sedimentólogos que distingem as areias de duna, das provenientes de outros ambientes, por possuírem assimetria positiva. No entanto, as características granulométricas das amostras estudadas poderão justificar-se pela existência de ventos fortes longilitorais, responsáveis pelo transporte das areias da duna branca para o interior, quando a praia alta é reduzida ou inexistente e por estes sistemas incluírem desembocaduras fluviais que, antes de estabilizadas, migravam ao longo dos cordões e por vezes os inundavam, depositando os sedimentos transportados. Em alguns casos a destruição antrópica das dunas originou novos corredores de deflação, onde os ventos se abasteceram de areias mais finas ou mais grosseiras com origem fluvial e/ou marinha, originando remobilização e mistura de sedimentos, ou mesmo o aparecimento à superfície de sedimentos mais grosseiros, pertencentes aos cordões litorais que suportam as dunas. Daí, a elevada polimodalidade das amostras e a existência de assimetrias negativas que denunciam a presença de areias mais finas ou mais grosseiras, em sedimentos com médias granulométricas correspondentes a areias grosseiras a médias.

A presença de cordões dunares duplos na Nazaré, em S. Martinho do Porto e no tômbolo de Peniche, pode estar relacionada com restingas acumuladas em períodos de relativa estabilidade do mar a níveis ligeiramente diferentes. A depressão que os divide terá resultado de uma ligeira descida do mar, na «Pequena Idade do Gelo» ocorrida entre os séculos XIV e XIX, com maior intensidade nos séculos XVI e XVII (FonT-Tullot, 1986). Este período coincide com o registo do abandono dos portos marítimos interiores, devido ao assoreamento (HENRiQues, 1996).

Nos casos estudados, a dinâmica litoral dos sistemas dunares e de praia foi marcada até ao século XIX por um balanço sedimentar positivo. A actual evolução das formas e a erosão verificada (natural e antrópica) indicam inversão da tendência evolutiva: dinâmica de carácter regressivo prevalecente até finais do século XIX, que em meados do século XX deu lugar a uma dinâmica de tendência transgressiva.

Do ponto de vista biogeográfico a área estudada está totalmente inserida no superdistrito Costeiro Português, província Gaditano Onubo Algarviense. Este superdistrito é um território litoral que se estende para norte do Cabo da Roca até Aveiro, dominado por praias, dunas de areia e calcários. A litologia e 
morfologia observadas permitem a organização das comunidades vegetais em dois grandes grupos:

1 - Comunidades próprias de substratos ácidos, móveis (areias de praia e dunares).

2 - Comunidades próprias de arribas litorais calcárias e de solos básicos derivados dos referidos calcários, no topo das arribas.

As comunidades psamofílicas que caracterizam a área dunar estudada organizam-se, quanto às características morfopedoecológicas e florísticas, em 4 grupos:

A-Comunidades de praia: nas praias da área estudada ocorrem 2 associações:

1 -Salsolo kali-Cakiletum aegyptiacae. Comunidade halonitrofílica e psamofílica, dominada por terófitos pioneiros que, de forma aberta, se instalam preferencialmente na parte superior da praia média ou na transição para a praia alta, onde têm de suportar influência directa e permanente do sal, no solo e no ar, movimentação constante e fácil do substratos arenoso, acção permanente do vento e por vezes da ondulação. É muito pobre em espécies que se desenvolvem sobre detritos orgânicos transportados pelo mar. Espécies características mais importantes: Cakile maritima, Euphorbia peplis, Salsola kali.

2 -Euphorbio-Agropyretum junceiformis. Comunidade tipicamente psamofílica, com baixa cobertura que coloniza as areias da praia alta até à frente da praia, em especial nos sectores planos, invadidos pela ondulação nas tempestades e marés vivas. É formada por uma vegetação halopsamofílica dominada por hemicriptófitos sujeitos à acção das vagas durante as tempestades e submetido à forte movimentação das areias. Espécies características mais importantes: Elymus boreali-atlanticus, Eryngium maritimum, Euphorbia paralias, Calystegia soldanella, Pancaratium maritimum, Medicago marina, Polygonum maritimum.

B-Comunidades de dunas móveis: Loto cretici-Ammophiletum australis. É a comunidade dominada por Ammophila australis que coloniza, com elevada densidade, as cristas das dunas embrionárias da praia alta (nebkas da praia alta) e as dunas móveis influenciadas pela salsugem. Relativamente às comunidades características do ecossistema de praia (Euphorbio-Agropyretum e Salsolo-Cakiletum), a associação Loto cretici-Ammophiletum australis apresenta maior diversidade florística. Espécies características mais importantes: Ammophila australis, Otanthus maritimus, Eryngium maritimum, Calystegia soldanella, Euphorbia paralias, Pancaratium maritimum, Lotus creticus, Medicago marina, Herniaria maritima, Polygonum maritimum. 
C - Comunidades das dunas penestabilizadas:

1 -Amerio welwitschii-Cruciannelletum maritimae. Comunidade camefítica própria das dunas penestabilizadas litorais dominadas por Armeria welwitschii. Trata-se de uma comunidade permanente nas dunas penestabilizadas entre o Tejo e a Figueira da Foz, mas pode também representar uma etapa de degradação do sabinal psamofílico próprio das dunas estabilizadas Osyrio-Juniperetum turbinatae. As espécies características dominantes e/ou mais importantes são: Armeria welwitschii, Artemisia maritima, Crucianella maritima, Scrophularia frutescens, Helichrysum picardii.

2 -Rubio longifoliae-Coremetum albi. É uma comunidade tipicamente termófila e heliofítica dominada por Corema album que representa a orla natural ou primeira etapa de substituição dos sabinais litorais de Juniperus turbinata (Osyrio-Juniperetum turbinatae). De composição florística muito simples esta comunidade forma um mato, por vezes denso e alto, de Corema album, Antirrhinum cirrhigerum, Rubia longifolia e Asparagus aphyllus, que cobre totalmente o solo.

D - Comunidades características das dunas estabilizadas. Estas comunidades organizam-se em duas séries de vegetação:

1 - Série da sabina-da-praia que coloniza as dunas estabilizadas ainda submetidas à influência da salsugem, Osyrio quadripartitae-Juniperetum turbinatae. É uma formação arbustiva densa e de elevado porte, dominada por fanerófitos (micro e nanofanerófitos). Nas dunas litorais estabilizadas, a pobreza do solo e a influência directa dos ventos marítimos impossibilitam a existência de bosques da classe Quercetea ilicis. Assim, o mato de sabina-da-praia constitui a etapa madura do sistema (série edafoxerófita termomediterrânica, psamofílica litoral de Juniperus turbinata). Do ponto de vista florístico a comunidade é dominada por Juniperus turbinata, Rubia longifolia, Pistacia lentiscus, Rhamnus oleoides e Rhamnus alaternus.

2 - Série dos samocais/medronhais que colonizam as dunas estabilizadas mais interiores, não afectadas pela influência da salsugem, Myrico faiae-Arbutetum unedonis. Constitui um nanobosque de Arbutus unedo e Myrica faia (arbórea), assentes em solos florestais com humus mull. Esta vegetação corresponde à etapa climax da microssigmassociação das dunas verdes antigas costeiro portuguesas (Oeste-Estremenho, Divisório-Português), no andar mesomediterrânico sub-húmido (Capelo e Mesquita, 1998). 


\section{BIBLIOGRAFIA}

Abecassis, F. (1997) - Caracterização Geral Geomorfológica e Aluvionar da Costa Continental Portuguesa. Colectânea de ideias sobre a Zona Costeira de Portugal. Associação Eurocoast-Portugal, Lisboa: 9-24.

Bourcart, J. (1936) - Sur l'évolution du littoral de la Péninsule Ibérique, de la presqu'île de Peniche (Portugal), au Cap Finisterre (Galice Espagnole). C. R. Acad. Scienc, tomo 202, Paris: $1448-1458$.

Capelo, J. e Mesquita, S. (1998) - Nota sobre a vegetação natural potencial das dunas estabilizadas do Superdistrito Costeiro Português. Silva Lusitana, 6(2): 257 - 259.

Castroviejo, S. et al. (1986-1997) - Flora Iberica. (Plantas Vasculares da Península Ibérica e Islas Baleares). Madrid, Real Jardim Botánico, Volumes I a V.

Costa, J. C.; Capelo, J. H.; Lousã, M.; Aguiar, C. e Neto, C. (1998) - Biogeografia de Portugal Continental. Quercetea. Vol. 0: 1-56.

Coutinho, A. X. P. (1939) - Flora de Portugal. Plantas Vasculares, Livraria Bertrand, Lisboa, 2. ed.

CRUZ, C. S. (1984) - Estruturas dunares litorais de Portugal (considerações sobre fitogeodinâmica). Actas do Colóquio Nacional para a Conservação das Zonas Ribeirinhas. Liga para a Protecção da Natureza, 1 (18), 3. ${ }^{a}$ série, Lisboa: 173-205.

Ferreira, J. B. (1902) - As dunas de Portugal e a sua arborização. Boletim da Real Associação Central da Agricultura Portuguesa. Lisboa, 239-269.

FolK, K. L. e WARD, W. C. (1957) - Brazos River Bar. A study in the significance of grain size parameters. Journal of Sedimentary Petrology, 27 (1): 3-26.

Font-Tullot, I. (1986) - Cambios climáticos en la Peninsula Ibérica durante el último milénio, con especial referência a la Pequeña edad Glacial. Quaternary Climate in Western Mediterranean Proccedings. Madrid: 249-273.

Franco, A. e Afonso, M. da L. R. (1994) - Nova Flora de Portugal (Continente e Açores), Volume III (Fascículo I). Escolar Editora, Lisboa.

Franco, A. (1971) - Nova Flora de Portugal (Continente e Açores), Volume I (LYCOPODIACEAE - UMBILIFERAE). Lisboa.

Franco, A. (1984) - Nova Flora de Portugal (Continente e Açores), Volume II (CLETHRACEAE - COMPOSITAE). Lisboa.

FRANZINI, M. M. (1812) - Roteiro das costas de Portugal ou instruções régias para inteligência e uso da carta reduzida da mesma costa e dos planos particulares dos seus principais portos, dedicado a S.A.R. o P.R.N.S. Impressão Régia, Lisboa.

FRIEDMEN, G. M. (1961) - Distinction between dune, beach and river sands from their textural characteristics. Journal of Sedimentary Petrology, 31 (4): 514-529

FrIEDMEN, G.M. (1967) - Dynamic processes and statistical parameters compared for size frequency distribution of beach and river sands. Journal of Sedimentary Petrology, 37 (2): 327-354.

Henriques, M. V. F. J. (1996) - A faixa litoral entre a Nazaré e Peniche. Unidades geomorfológicas e dinâmica actual dos sistemas litorais. Dissertação de Doutoramento, Universidade de Évora (policopiado). Évora. 
INMG (1991) - Normais Climatológicas da região de Ribatejo e Oeste, 1951-1980. O clima de Portugal, Fasc. XLIX, 2, 2. ${ }^{\mathrm{a}}$ região. Lisboa.

Missão hidrográfica da costa de portugal (1923) - Costa Oeste de Portugal entre o rio Minho e o Cabo Carvoeiro, Ministério da Marinha, Direcção de Hidrografia, Lisboa:

- Plano Hydrográfico da Enseada da Pederneira, 1912, escala 1:12 300.

- Plano Hydrográfico da Enseada de Peniche, 1920, escala 1:15 000.

- Plano Hydrográfico de S. Martinho do Porto, 1915, escala 1:10 000.

Neto, C. S. (1993) - A Flora e a Vegetação das Dunas de S. Jacinto. Finisterra, XXVIII, 55-56: 101-148.

Ribeiro, C. e Delgado, N. (1868) - Relatório acerca da arborização geral do País. Tipografia da Academia Real das Sciências. Lisboa.

Valdés, B.; Talavera, S. e Galiano, E. F. (1987) - Flora Vascular de Andalucía Ocidental, Vols.I,II e II. Ketres editora, Barcelona. 
APÊNDICE - Elenco florístico da área estudada

\begin{tabular}{|c|c|c|c|c|c|}
\hline Ammophila arenaria ssp. arundinacea & $\mathrm{He}$ & $\mathrm{Db}$ & Lavandula pedunculata ssp. lusitanica & $\mathrm{Ca}$ & Dc \\
\hline Anagallis monelli var. microphylla & $\mathrm{Ca}$ & Dc & Leontodon taraxacoides ssp. taraxacoides & $\mathrm{He}$ & Dc \\
\hline Antirrhinum majus ssp. cirrhigerum & $\mathrm{Ca}$ & Dc & Limonium multiflorum & $\mathrm{He}$ & Ac \\
\hline Armeria welwitschii spp. cinerea & $\mathrm{Ca}$ & Ac & Limonium ovalifolium & $\mathrm{He}$ & Ac \\
\hline Armeria welwitschii spp. welwitschii & $\mathrm{Ca}$ & Dc & Limonium plurisquamatum & $\mathrm{He}$ & Ac \\
\hline Artemisia campestris ssp. maritima & $\mathrm{Ca}$ & Dc & Limonium virgatum & $\mathrm{He}$ & Ac \\
\hline Asparagus aphyllus & $\mathrm{Na}$ & Dv & Lotus creticus & $\mathrm{He}$ & $\mathrm{Db}$ \\
\hline Cakile maritima ssp. maritima & Te & $\mathrm{P}$ & Malcolmia littorea & $\mathrm{Ca}$ & $\mathrm{Db}$ \\
\hline Calystegia soldanella & $\mathrm{He}$ & $\mathrm{Db}$ & Medicago marina & $\mathrm{Ca}$ & Dc \\
\hline Carpobrotus edulis & $\mathrm{Ca}$ & Dc & Olea europeia var. sylvestris & $\mathrm{Me}$ & Dv \\
\hline Cerastium glomeratum & Te & $\mathrm{Db}$ & Ononis natrix ssp. hispanica & $\mathrm{Na}$ & Dc \\
\hline Cistus salvifolius & $\mathrm{Na}$ & Dv & Otanthus maritimus & $\mathrm{Ca}$ & $\mathrm{P}$ \\
\hline Corema album & $\mathrm{Na}$ & Dv & Pancaratium maritimum & Ge & $\mathrm{P}$ \\
\hline Corynephorus canescens var. maritimus & $\mathrm{He}$ & Dc & Phillyrea angustifolia & $\mathrm{Na}$ & Dv \\
\hline Crithmum maritimum & $\mathrm{He}$ & Ac & Pinus pinaster & $\mathrm{Me}$ & Dv \\
\hline Crucianella maritima & $\mathrm{Ca}$ & Dc & Pinus pinea & Me & Dv \\
\hline Dactylis marina & $\mathrm{He}$ & Ac & Pistacia lentiscus & $\mathrm{Mi}$ & Dv \\
\hline Daphne gnidium & $\mathrm{Na}$ & Dv & Plantago coronopus ssp. occidentalis & $\mathrm{He}$ & Ac \\
\hline Daucus halophilus & $\mathrm{He}$ & Ac & Polygonum maritimum & $\mathrm{Ca}$ & $\mathrm{P}$ \\
\hline Dittrichia viscosa ssp. viscosa & $\mathrm{Ca}$ & Dv & Quercus coccifera & $\mathrm{Mi}$ & Dv \\
\hline Elymus farctus ssp.boreali-atlanticus & $\mathrm{He}$ & $\mathrm{P}$ & Reichardia gaditana & $\mathrm{He}$ & Dc \\
\hline Eryngium maritimum & $\mathrm{He}$ & $\mathrm{Db}$ & Rhamnus lycioides ssp. oleoides & $\mathrm{Na}$ & Dv \\
\hline Euphorbia paralias & $\mathrm{He}$ & $\mathrm{Db}$ & Rubia peregrina & $\mathrm{Ca}$ & Dv \\
\hline Euphorbia peplis & Te & $\mathrm{P}$ & Rumex bucephalophorus ssp. hispanicus & $\mathrm{Te}$ & Dc \\
\hline Euphorbia terracina & $\mathrm{He}$ & Dc & Salsola kali ssp. kali & $\mathrm{Te}$ & $\mathrm{P}$ \\
\hline Halimium halimifolium ssp. multiflorum & $\mathrm{Na}$ & Dv & Scrophularia frutescens & $\mathrm{Ca}$ & Dc \\
\hline Helichrysum italicum ssp. picardii & $\mathrm{Ca}$ & Dc & Sedum sediforme & $\mathrm{Ca}$ & Dc \\
\hline Herniaria ciliolata ssp. robusta & $\mathrm{Ca}$ & Dc & Seseli tortuosum & $\mathrm{He}$ & Dc \\
\hline Holoschoenus romanus ssp. australis & Ge & $\mathrm{Dh}$ & Silene littorea & $\mathrm{Te}$ & $\mathrm{Db}$ \\
\hline Iberis procumbens ssp. procumbens & $\mathrm{Ca}$ & Dc & Smilax aspera var. altissima & $\mathrm{Fa}$ & Dv \\
\hline Jasione lusitanica & $\mathrm{Ca}$ & Dc & Spergularia australis & $\mathrm{Ca}$ & Ac \\
\hline Juniperus turbinata ssp. turbinata & $\mathrm{Mi}$ & Dv & Ulex densus & $\mathrm{Ca}$ & Ac \\
\hline Lagurus ovatus & Te & I & Vulpia alopecurus & $\mathrm{Te}$ & Dc \\
\hline $\begin{array}{l}\mathrm{Me} \text { - mesofanerófito } \\
\mathrm{Mi} \text { - microfanerófito } \\
\mathrm{Na} \text { - nanofanerófito } \\
\mathrm{Fa} \text { - fanerófito escandente } \\
\mathrm{Ca} \text { - caméfito } \\
\mathrm{He} \text { - hemicriptófito } \\
\mathrm{Ge} \text { - geófito }\end{array}$ & & & $\begin{array}{l}\text { P - Praia } \\
\text { Db - Duna branca } \\
\text { Dc - Duna cinzenta } \\
\text { Dv - Duna verde } \\
\text { Dh - Depressão húmida } \\
\text { Ac - Arribas calcárias } \\
\text { I - Indiferente }\end{array}$ & & \\
\hline
\end{tabular}

